\title{
A method for visualizing fluorescence of flavonoid therapeutics in vivo in the model eukaryote Dictyostelium discoideum
}

$\overline{\text { Billy T Ferrara' \& Elinor P Thompson*,1 }}$

\section{ABSTRACT}

Naturstoff reagent $A$ (diphenylboric acid 2-aminoethyl ester [DPBA]) has been used historically in plant science to observe polyphenolic pigments, such as flavonoids, whose fluorescence requires enhancement to be visible by microscopy. Flavonoids are common dietary constituents and are the focus of considerable attention because of their potential as novel therapies for numerous diseases. The molecular basis of therapeutic activity is only gradually being established, and one strand of such research is making use of the social amoeba Dictyostelium discoideum. We extended the application of DPBA to flavonoid imaging in these preclinical studies, and report the first method for use of DPBA in this eukaryotic model microbe and its applicability alongside subcellular markers. This in vivo fluorescence imaging provided a useful adjunct to parallel chemical and genetic studies.

\section{METHOD SUMMARY}

Flavonoids at physiological concentrations emit only low levels of fluorescence, which are not visible by microscopy in situ. A dye that has been used to enhance fluorescence of polyphenolic pigments in plant tissues was found to be effective in studies of flavonoid therapeutics in a model eukaryotic microbe, Dictyostelium discoideum. Use of a simple buffer and fixative on treated cells allows flavonoid transport and localization to be monitored in vivo, using epifluorescence and confocal microscopy.

\section{KEYWORDS}

Dictyostelium • flavonoid • fluorescence $\cdot$ microscopy

'School of Science, University of Greenwich, Chatham Maritime, ME4 4TB, UK *Author for correspondence: te30@gre.ac.uk

BioTechniques 66: 65-71 (February 2019) 10.2144/btn-2018-0084

\section{INTRODUCTION}

Flavonoids constitute a large family of polyphenolic compounds that have been widely suggested to endow health benefits, ranging from anticancer, anti-inflammatory, antiviral and anti-allergic activity, through to treatment of diabetes and Alzheimer's disease [1-3]. Flavonoids are not synthesized by animals or their gut microbiota but are abundant in our diet because they are secondary metabolites of plants. They act as pigments and bitter flavours, attracting pollinators or protecting against UV and herbivory, but can also modulate plant development and root-microbial symbioses [4-6]. The anti-oxidant activity shared by many of these compounds has been hypothesized to underlie purported therapeutic benefits, and numerous studies do demonstrate links between health outcomes and flavonoids. The literature, however, does not describe well the specific transport, biological activity and chemical fate upon ingestion of individual compounds. These are subject to compound size, configuration, lipophilicity and solubility, and flavonoids possess diverse chemical subgroups and modifications, the latter including hydroxylation, glycosylation, methylation and polymerization (Figure 1) [7]. For example, such compound specificity was described previously for the activities of plant polyphenols: only a subset of flavonoids affects the transport of the plant hormone auxin, and thus plant development $[6,8,9]$. The biomedical literature has recently begun to follow suit, with reports of particular polyphenolic secondary metabolites acting via individual protein targets and reaching distinct subcellular compartments $[10,11]$. There is also limited evidence for some pathways of flavonoid metabolism in humans, namely glucuronidation, o-methylation, and addition of glutathione, depending on where the compounds are absorbed [12]. of note therapeutically, aglycones have been reported to be readily absorbed whereas glycosides must be transformed into the aglycone form $[13,14]$. Flavonoids, however, are most commonly found as glycosides in plants [15], so there are questions over transport of compounds even when robustly shown to have useful therapeutic activity.

Examples of evidence for activity of kaempferol (3,4',5,7-tetrahydroxyflavone) were the inhibition of growth of lung cancer lines [16] and induction of cancercell apoptosis [15]. Naringenin (4',5,7-trihydroxyflavanone) reduced cyst formation in both animal and in vitro studies of polycystic kidney disease (PKD): indeed its action via the PKD2 protein was first demonstrated in the model microbe Dictyostelium [11]. Furthermore, naringenin, kaempferol and quercetin $\left(3,3^{\prime}, 4^{\prime}, 5,7\right.$-pentahydroxyflavone) have been reported to inhibit phosphoinositide 3-kinase, nuclear factor $B$ pathway and kinases involved in pro-apoptic signaling in cancer cells $[17,18]$.

These polyphenolic compounds can be quantified in tissue extracts by UV-visible spectroscopy, HPLC, mass spectrometry methods and NMR $[19,20]$. Flavonoids exhibit only low levels of fluorescence, however, and cannot be viewed at physiologically relevant concentrations in vivo. A method was therefore developed several decades ago for visualizing them in plant tissues using the fluorescent probe Naturstoff reagent $A$ (diphenylboric acid 2-aminoethyl ester [DPBA]). The specificity of the probe for flavonoids was demonstrated in plants including Arabidopsis thaliana [21-23] and it has, infrequently, been applied in human in vitro cell cultures. For example, apigenin (4',5,7-trihydroxyflavone) was visualized in mitochondria of monocytic leukemia (THP-1) cells [24]; quercetin and kaempferol in the nucleus of umbilical endothelial cells; and quercetin at the cell membrane in epithelial colorectal adenocarcinoma cells $[7,25,26]$. 


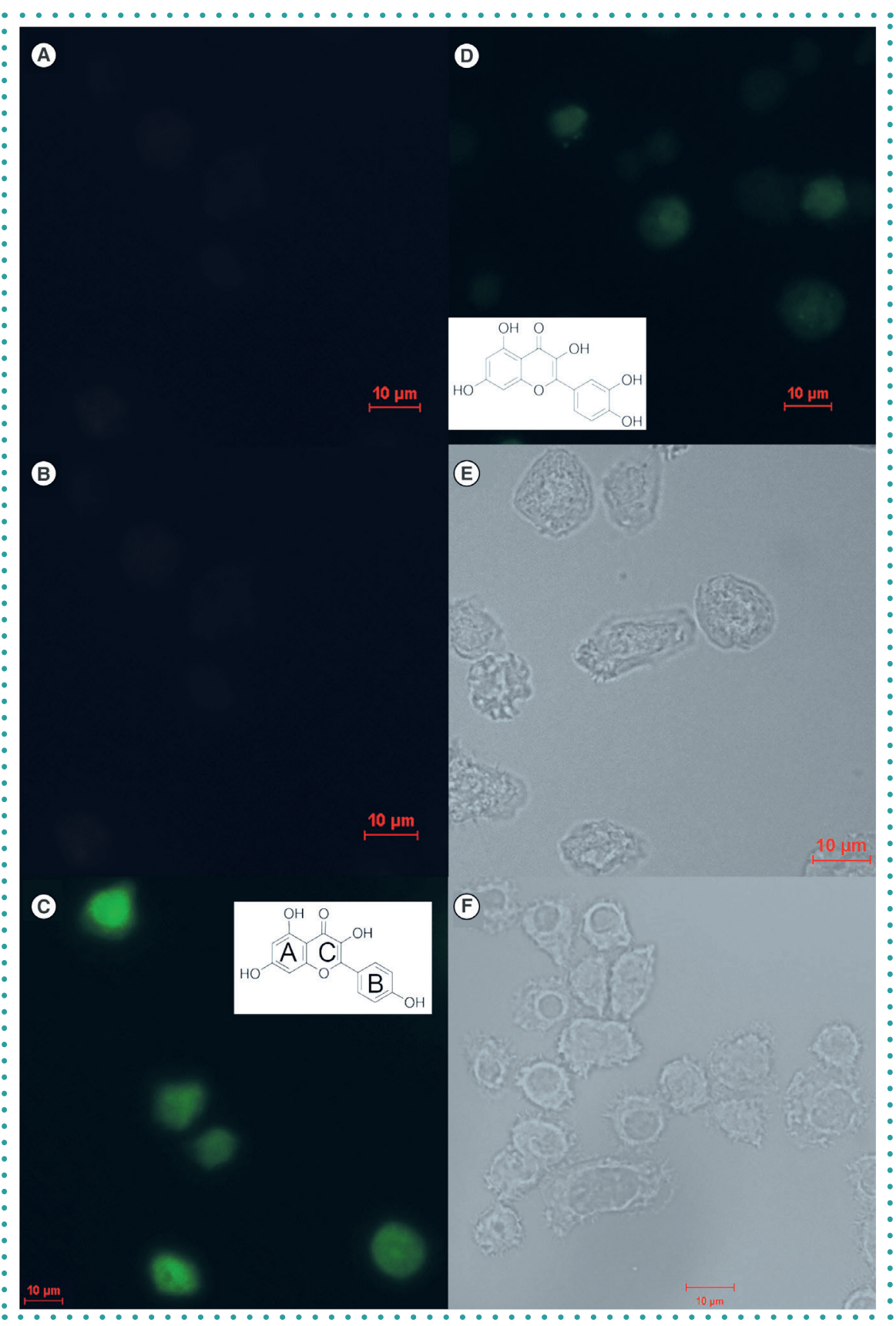

Figure 1. Epifluorescence microscopy testing for autofluorescence. In (A) untreated Dictyostelium cells vs (B) cells treated with DPBA vs cells exposed to $50 \mu \mathrm{M}$ flavonoid treatments for $30 \mathrm{~min}$ (C, kaempferol; D, quercetin). Bright field (E) DPBA- and (F) DMSO-treated Dictyostelium cells. Images acquired using Nikon Eclipse 90i, Ex 470nm - Em 525 x60 lens.

DBPA: Diphenylboric acid 2-aminoethyl ester; DMSO: Dimethyl sulfoxide.

- The mechanism by which the fluorescent probe binds to polyphenolics is not well described: it was proposed to form a spontaneous complex with flavonoids, resulting in an increase in fluorescence [27], but this is not the case for all members of the family. The use of DPBA was recorded by the German researcher Neu in 1961 [28], who described its synthesis by modifying Schiff's reagent with a nitrogen donor and cence emission from a range of polyphenolic compounds under UV excitation [29]. In 2011, Matteini et al. [30] described various possibilities for complex formation between DPBA and rutin $\left[3,3^{\prime}, 4^{\prime}, 5,7-\right.$ pentahydroxyflavone 3-(0-rhamnosylglucoside)] and hypothesized that DPBA could conjugate at two sites of the flavonoid backbone, either between the 5-hydroxy-4-keto sites of the A-C ring, or the 3-4-o-diphenolic site of the $B$ ring (Figure 1).

We explored further the utility of DPBA, with a range of plant or microbial metabolites whose biological activity was under investigation in a biomedical model microbe. The social amoeba Dictyostelium discoideum is a eukaryotic model organism whose life cycle includes phagocytosis of bacterial prey, before signaling and aggregation of motile cells leads to formation of a multicellular 'slug' with differentiated cell types [31]. It is an ideal biomedical model for various aspect of cell biology [32,33], and $D$. discoideum is also no stranger to flavonoid research. For example, a Dictyostelium mutant library was employed in the studies of naringenin, which identified the PKD2 cation-channel target [11] and of curcumin [34], and the amoeba was also employed to explore the chemotactic effect of bitter tastants [35]. Given the evidence for differential uptake of flavonoids, including long-distance transport [36], for involvement of specific transporter proteins $[9,37,38]$ and the possibility of efflux (unpublished data), there is a need to observe localization of flavonoid-treatment and target in vivo. We found that differential uptake and targeting of therapeutically relevant flavonoids in the model amoeba could be visualized, and flavonoid localization could be imaged along with other cell markers, using the DPBA probe.

\section{MATERIALS \& METHODS}

$D$. discoideum cells were grown axenically in HL5 medium (Formedium, Hunstanton, UK) at $22^{\circ} \mathrm{C}$ to a density of $10^{6} \mathrm{cell} / \mathrm{s} / \mathrm{ml}$. Cells were washed twice by pelleting $(500 \times \mathrm{g}, 4 \mathrm{~min})$ and resuspended in potassium dibasic (KK2) buffer. Cells were then pelleted and resuspended in LoFlo broth (Formedium) at $5 \times 10^{5}$ cells $/ \mathrm{ml}$ and re-incubated $\left(22^{\circ} \mathrm{C} 180 \mathrm{rpm}\right)$ for $24 \mathrm{~h}$. After incubation, cells were transferred to a Petri dish containing sterile coverslips: $15 \mathrm{ml}$ of cells at a final density of $5 \times 10^{6}$ cells/ $\mathrm{ml}$ in LoFlo were allowed to settle onto the coverslips for $30 \mathrm{~min}$. 
For treatment with flavonoids, the appropriate molarity of the compound of interest was prepared using a maximum of $0.1 \%$ dimethyl sulfoxide (DMSO) in deionized water (no flavonoid, versus final concentrations of DMSO, were $25 \mu \mathrm{M}, 0.025 \% ; 50 \mu \mathrm{M}$, $0.05 \% ; 100 \mu \mathrm{M}, 0.1 \%)$. The selected treatment was added to the $15 \mathrm{ml}$ LoFlo broth in a Petri dish, into which the coverslips and attached cells were transferred. Incubation for $30 \mathrm{~min}$ (or 0, 20, 40 or 60 min for time-course assay) at $22^{\circ} \mathrm{C}$ was followed with rinsing, by dipping coverslips in $0.1 \mathrm{M}$ potassium phosphate buffer (PPB) pH6.8, then drying excess liquid from the glass with filter paper (Whatmann, Maidstone, UK), by capillary action.

For imaging, $0.1 \% \mathrm{w} / \mathrm{v}$ DPBA solution in ethanol was pipetted onto treated, adhered cells on coverslips, and allowed to stain for $5 \mathrm{~min}$. DPBA was rinsed from coverslips by dipping into $0.1 \mathrm{M}$ PPB once more, and blotting dry with filter discs again. Where required, cells were treated with organelle stains (DAPI [ $1 \mu \mathrm{g} / \mathrm{ml}$; Abcam, Cambridge, UK]), MitoTracker (100 nM; Fisher) or FM4-64 ( $5 \mu \mathrm{g} / \mathrm{ml}$; Fisher) according to the manufacturer's protocol, before (MitoTracker) or after (DAPI, FM4-64) treatment and DPBA staining.

Treated and stained cells on coverslips were then fixed with $2 \%$ v/v paraformaldehyde (in phosphate-buffered saline [PBS] $\mathrm{pH} 7$ ) for $20 \mathrm{~min}$, and the excess rinsed off using PBS before a further filter-paper blot to dry. One drop of $1 \% \mathrm{v} / \mathrm{v} \mathrm{n}$-propyl gallate mounting medium (in glycerol:PBS 60:40\% $\mathrm{v} / \mathrm{v} ; \sim 5-10 \mu \mathrm{l}$ ) was added to microscope slides and coverslips mounted to slides. Coverslips were sealed to slides using nail polish, samples viewed by epifluorescence or confocal microscopy (LSM 880, Zeiss, Cambridge, UK) and images processed using ZEN software (Zeiss). Fixed samples were stored at $-20^{\circ} \mathrm{C}$.

All experiments were performed a minimum of three times, with a minimum of three biological replicates per experiment.

\section{RESULTS \& DISCUSSION}

\section{DPBA-enhanced}

\section{epifluorescence microscopy}

To determine whether DPBA-enhanced fluorescence emission could be successfully employed in Dictyostelium, cells were first viewed with and without DPBA treatment, via epifluorescence using the
UV2A cube (Nikon) that limits excitation wavelength to $330-380 \mathrm{~nm}$ and emission to $\geq 420 \mathrm{~nm}$, to check for autofluorescence. Cells grown axenically had been transferred to low-fluorescence medium and, following incubation, images were acquired using epifluorescence microscopy. Since there was no background cell autofluorescence (Figure 1A) in untreated wild type (AX2) cells nor cells treated with $0.1 \%$ (w/v) DPBA (Figure 1B), our protocol for visualizing plant native flavonoids [9] was modified for use with this model microbe. Three test flavonoids were chosen according to welldocumented activity (as summarized above) in tissue culture, or from study using Dictyostelium, and concentrations for treatment were guided by those reports and parallel studies here of viability and lifecycle progression in Dictyostelium (Supplementary Figure 1). Cells were therefore treated with $50 \mu \mathrm{M}$ kaempferol, naringenin and quercetin for $30 \mathrm{~min}$. With addition of DPBA to prepared samples, epifluorescence could be used to view cells adhered to microscope slides that had undergone a time-course of treatment up to $60 \mathrm{~min}$ incubation with test flavonoid: it was possible to visualize kaempferol and quercetin after treatments of $\sim 20 \mathrm{~min}$ (Figure 1C \& D), and low fluorescence from naringenin was observed after $\sim 40 \mathrm{~min}$. Without the use of the flavonoid fluorescence enhancer, no signal was observed from $D$. discoideum cells treated with any flavonoid (Supplementary Figure 2) and no fluorescence was detected in solvent (DMSO)/DPBA controls (Supplementary Figure 2). The fluorescent probe therefore did permit in vivo visualization of flavonoid fluorescence for three flavonoids of therapeutic interest in this model microbe.

\section{Dosage assay}

Biological and transcriptional responses, such as cell rounding and toxin transporter upregulation were observed when Dictyostelium was treated with kaempferol, naringenin or quercetin at $10-50 \mu \mathrm{M}$, viability only declining for one compound, namely kaempferol with treatment of $100 \mu \mathrm{M}$ (Supplementary Figure 1). To discern concentration-dependent effects by imaging, cells were therefore incubated (20 min) with $0-100 \mu \mathrm{M}$ treatment and $0.1 \%$ DPBA: the resultant fluorescence signal in amoeba was enhanced in line with increasing concentration. As before, kaempferol (Figure 2) and quercetin were most easily detectable, at concentrations $\geq 25 \mu \mathrm{M}$, whereas naringenin fluorescence was not observed below $50 \mu \mathrm{M}$ and was most visible at $100 \mu \mathrm{M}$ (Supplementary Figure 3).

\section{Time-course assay}

The physiologically relevant $50 \mu \mathrm{M}$ concentration was then used in a time-course experiment. Differential accumulation of flavonoids (Figures $1 \& 2$ ) again occurred in Dictyostelium as seen in other organisms and cell types [7,36], since quercetin fluorescence was visible after 10-min incubation, whereas for kaempferol visualization a treatment of at least 20 min was required. Naringenin required the longest incubation for detectable fluorescence, becoming most easily visible after $60 \mathrm{~min}$ of treatment (Supplementary Figure 4).

\section{Confocal microscopy of co-localization dyes in conjunction with \\ fluorescence enhancement}

An increase in fluorescence could be the result of flavonoids bound to the surface of Dictyostelium cells rather than differential uptake. Therefore more sensitive, confocal, microscopy was employed and cell extracts were subjected to LCMS quantification to monitor flavonoid levels within cells. As noted above, dependent on cell type tested, flavonoids have been reported to localize to the nucleus or mitochondria, or the plant cell vacuole. To test if co-localization dyes could be used in conjunction with DPBA to allow subcellular location of flavonoids to be identified, Dictyostelium cells were treated with $50 \mu \mathrm{M}$ of naringenin, quercetin or kaempferol, viewed using $488 \mathrm{~nm}$ excitation and $520 \mathrm{~nm}$ emission, along with the DAPI nuclear marker (excitation $405 \mathrm{~nm}$, emission $461 \mathrm{~nm}$ ), FM4-64 (excitation 561 nm, emission $737 \mathrm{~nm}$ ) for plasma or vacuole membranes, or MitoTracker Red (excitation $561 \mathrm{~nm}$, emission $599 \mathrm{~nm}$ ) to stain the mitochondria [39-41].

Using the confocal microscope improved image quality when viewing DPBA-enhanced fluorescence and it was possible, as hoped, to visualize subcellular fluorescence from standard organelle markers as well as from the DPBA-flavonoid. A previous report on subcellular localization stated that a 


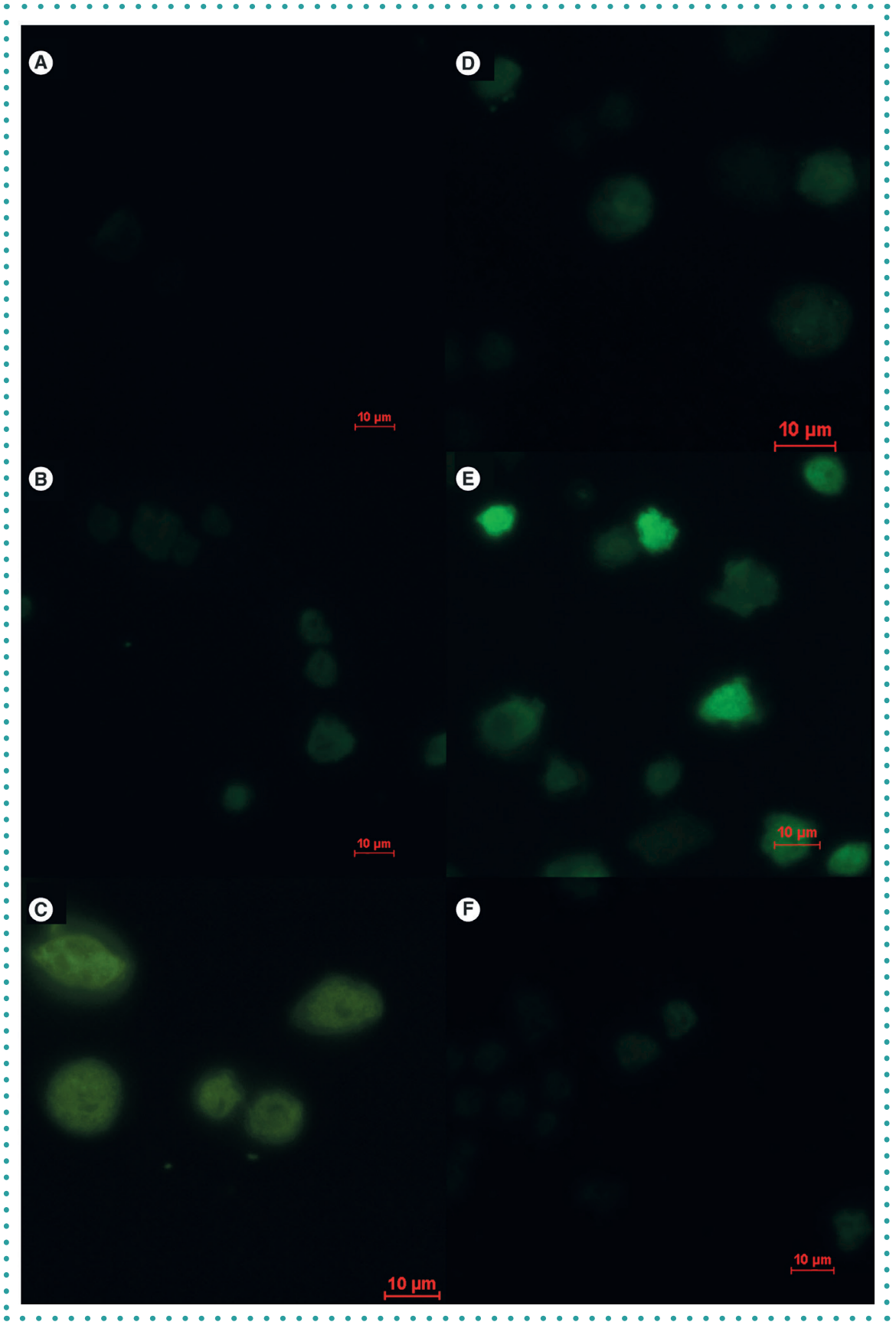

Figure 2. Epifluorescence microscopy of flavonoid-DPBA-treated Dictyostelium discoideum at concentrations of (A) $25 \mu \mathrm{M}$, (B) $50 \mu \mathrm{M}$ and (C) $100 \mu \mathrm{M}$ kaempferol; (D) $50 \mu \mathrm{M}$ and (E) $100 \mu \mathrm{M}$ quercetin; $(F) 100 \mu \mathrm{M}$ naringenin. For all treatments, see supplementary data. Images acquired using Nikon Eclipse 90i, Ex 470nm - Em 525 x60 lens.

> range of flavonols might reach the nuclei of cancer cells and induce DNA cleavage [42] and that quercetin reduced oxidative DNA damage and quenched free radicals in isolated DNA in vitro [43]. This co-treatment protocol, however, revealed that points of brightest fluorescence from the three test flavonoids did not occur at the nucleus, the fluorescence from kaempferol (Figure 3), naringenin and quercetin (Supplementary in agreement with the purported anti-oxidant properties of flavonoids: both quercetin and kaempferol were previously suggested to be cytotoxic to cancer cell lines by stimulating the mitochondria to overproduce ATP [46-48]. FM4-64 stained the plasma membrane and was internalized over time so that at 15 min it could be seen within Dictyostelium cells, at the contractile vacuole. The merged kaempferol and FM4-64 staining overlapped (Figure 3), in agreement with high kaempferol levels (Supplementary Figure 6) confirmed by LCMS in cell extracts (Supplementary Table 1).Figure 3. Confocal microscopy of flavonoid-DPBA-treated Dictyostelium discoideum with concurrent use of cell markers. FM4-64 plasma membrane/contractile vacuole co-staining ( $15 \mathrm{~min}$ ) after treatment with flavonoid (30 min). (A) Control, no treatment with flavonoid; (B) L-R: FM4-64, $50 \mu \mathrm{M}$ kaempferol, merge; (C) L-R: FM4-64, $50 \mu \mathrm{M}$ quercetin, merge. DAPI nuclear co-staining (followed 30 min flavonoid treatment); (D) L-R: $50 \mu \mathrm{M}$ kaempferol, DAPI, merge. MitoTracker mitochondrial co-staining (for $\mathbf{3 0} \mathrm{min}$ before $\mathbf{3 0} \mathrm{min}$ flavonoid treatment); (E) L-R: MitoTracker, $50 \mu M$ quercetin, merge. See also supplementary data; images acquired with Zeiss confocal LSM 880 x63 lens. L: Left; R: Right.

Parallel LCMS detection of flavonoids (Supplementary Table 1) showed naringenin was present in cell washes not cell extracts, and suggested significant quantities were not actively imported into Dictyostelium cells and that flavonoid fluorescence was imaged at the cell exterior. This was in agreement with the low fluorescence emission from naringenin seen in the dosage study (Figure 2), and the peripheral location of its reported target protein, PKD2, at the plasma membrane of both MDCK [49] and D. discoideum cells [50].

\section{Use of fluorescence enhancement with specific flavonoid subtypes}

Whereas three flavonoids were initially successfully imaged in Dictyostelium, in vitro assays of human cells detected DPBAenhanced fluorescence from apigenin (in macrophages) [41] and hesperetin (3',5,7-trihydroxy-4'-methoxyflavanone; in Caco2 cells) [7]. By contrast, our LCMS measurements showed that Dictyostelium cells were able to import the flavones apigenin and luteolin (3',4',5,7-tetrahydroxyflavone) and the flavanone hesperetin (the 
latter being slow to accumulate, however), none of these were visible using confocal or epifluorescence microscopy of flavonoid-DPBA-treated Dictyostelium cells. The mechanisms for flavonoid influx into human cells have not been fully elucidated and observations have been reported to differ based on flavonoid, cell type and sample preparation, and this might equally apply to amoebae. There may be more passive diffusion of the less-polar aglycones [41] than of the more commonly found glycoside forms [51]. The extent of this is not known versus active transport and efflux, although our chemical inhibition studies suggest that flavonoid efflux is an active process (manuscript in preparation). The differences in flavonoid influx previously reported are in agreement with the treatment length and concentration here both being seen to influence flavonoid detection via DPBA-enhanced imaging. In this study, quercetin was rapidly transported by Dictyostelium cells, being visible at $25 \mu \mathrm{M}$ after $10 \mathrm{~min}$, and kaempferol was also detectable after $25 \mu \mathrm{M}$ treatment for 20 min incubation (Figure 2). Naringenin was only minimally imported or not at all, requiring higher concentrations of 50-100 $\mu \mathrm{M}$ and requiring longer incubation for fluorescence to become visible (Figure 2, Supplementary Figure $2 \& 3$ ). Therapeutic use of naringenin is still possible, however, since it can exert a biological effect via the PKD2 target that is located at the cell boundary [49].

\section{Chemical basis for DPBA conjugation}

Searches of over half a century of literature yielded little detail of the mechanisms of DPBA-polyphenolic conjugation, but it was reported that the chemical structure of a compound determined both whether DPBA-enhancement of fluorescence emission occurs and its wavelength [30]. A hydroxyl group at the C3 position of the flavonoid skeleton (Figure 1) was suggested to be essential for fluorescence [39]. The flavanone naringenin is interesting in this respect, as it demonstrated weak DPBAenhanced fluorescence in Dictyostelium, despite missing the hydroxyl group in the $3^{\prime}$ position of the C-ring (Figure 1), in contrast with hesperitin, which was not visible. Another report suggested a minimum of two hydroxyl groups were required [29] but, again, the chemical structure of naringenin fits this criterion for conjugation with DPBA. The low fluorescence of this compound in vivo may correlate with low concentrations bound to the cell surface, along with little import of naringenin.

Such differential accumulation of flavonoids is in agreement with other research, and underlines both the need for further studies of transport and bioavailability and the usefulness of in vivo imaging. Mouse liver hepatoma cells (HEPA-1c1c7), human umbilical vein endothelial cells (HUVEC), mouse neuroblastoma cells (Neuro 2A) and human epithelial colorectal Caco-2 cells [24-26] all showed different levels of accumulation of specific flavonoids, clearly pertinent to medical application of flavonoids as therapeutic compounds. The in vivo imaging method developed here is superior to LCMS and HPLC in not requiring cell fractionation nor solvent extraction of cellular components and compounds, and takes much less time. The evolutionary conservation of flavonoid targets in Dictyostelium and human cells and its popularity as a model organism means that this DPBA-enhanced in vivo imaging can be a useful adjunct to the necessary research on the mechanism of entry, selectivity and exit of flavonoids. In summary, DPBAenhanced imaging can be used to reveal an association of flavonoids with Dictyostelium cells that can be viewed very simply with epifluorescence microscopy. For more detailed localization and dynamics of uptake, DPBA-enhanced confocal microscopy, and analytical chemistry for quantification, should be carried out. Identifying a compound's location in this model organism will help inform work on cellular targets, and ultimately progress the development of flavonoids from widely reported nutraceuticals to licensed therapies.

\section{FUTURE PERSPECTIVE}

Fluorescence imaging is a rapidly developing area. This most vital tool in science was established with longstanding techniques such as the use of ethidium bromide's intercalation into DNA to visualize nucleic acids in agarose gel electrophoresis; the binding of DAPI into the minor groove of DNA providing a subcellular (nucleus) marker; fluorogenic indicators permitting quantification of enzyme biochemistry; and native fluorescent compounds that indicate response to the environment - for example the ratio of chlorophyll a:b in plants. Confocal fluorescence microscopy has since become invaluable with the development of fluorescent reporter proteins, protein-interaction techniques such as BiFC, and further subcellular localization markers. Now, fluorescence utilizing nanoparticles and the range of fluorophores entering the market herald an era where all novel chemical entities and dynamic processes in cells can be viewed in vivo and in real time - for pharmaceutical science, this can illuminate, as in this study, the transport into and efflux from cells, which is often a key challenge in drug development.

Flavonoids have serendipitous attributes for imaging: the ability to enhance their fluorescence with the compound DPBA has been enormously useful for visualizing in vivo where these compounds are synthesized and transported within the plant. With the aim of reducing the need for studies using animals, DPBA protocols 


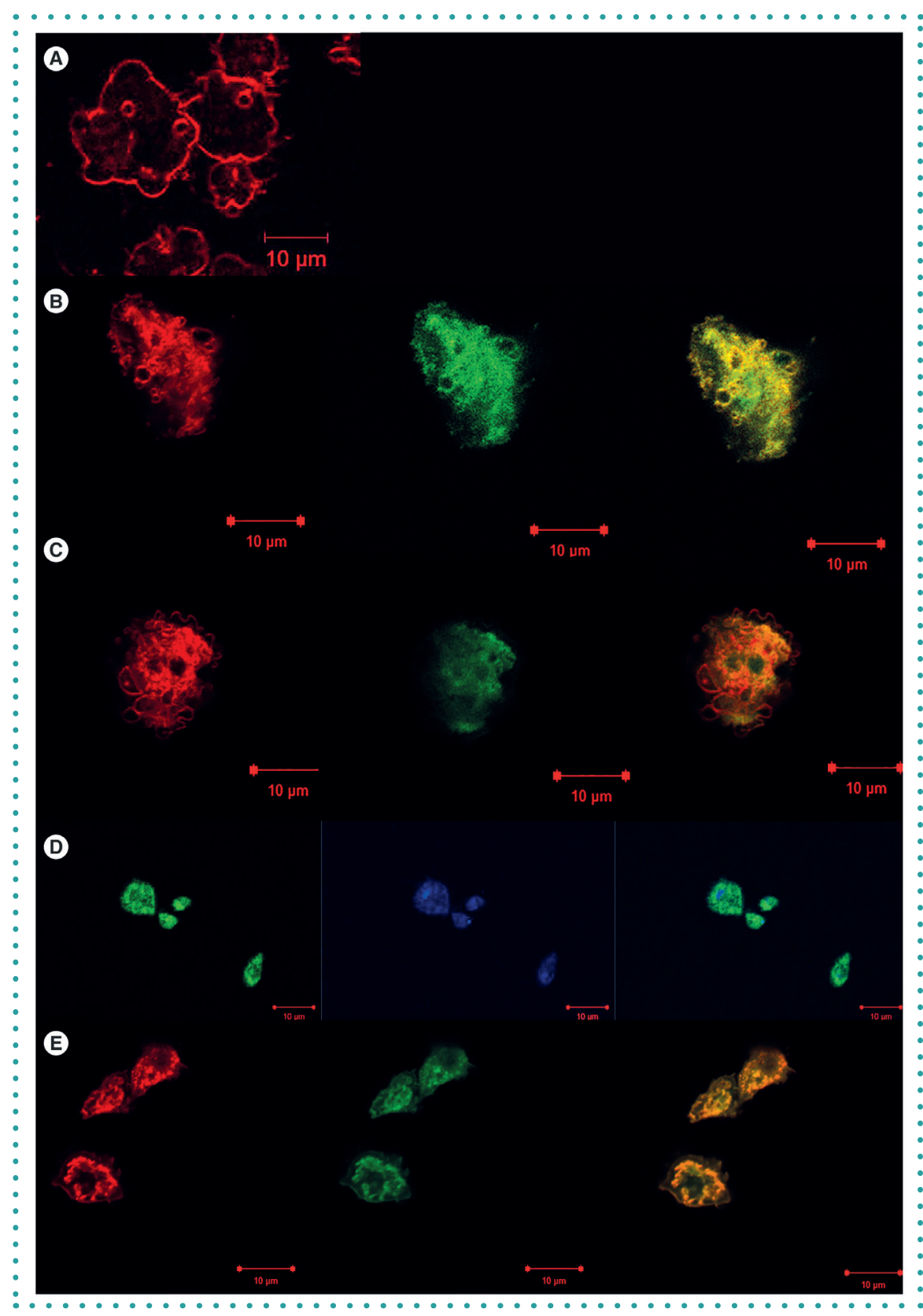

Figure 3. Confocal microscopy of flavonoid-DPBA-treated Dictyostelium discoideum with concurrent use of cell markers. FM4-64 plasma membrane/contractile vacuole co-staining ( $15 \mathrm{~min}$ ) after treatment with flavonoid (30 min). (A) Control, no treatment with flavonoid; (B) L-R: FM4-64, $50 \mu \mathrm{M}$ kaempferol, merge; (C) L-R: FM4-64, $50 \mu \mathrm{M}$ quercetin, merge. DAPI nuclear co-staining (followed 30 min flavonoid treatment); (D) L-R: $50 \mu \mathrm{M}$ kaempferol, DAPI, merge. MitoTracker mitochondrial co-staining (for $30 \mathrm{~min}$ before $30 \mathrm{~min}$ flavonoid treatment); (E) L-R: MitoTracker, $50 \mu \mathrm{M}$ quercetin, merge. See also supplementary data; images acquired with Zeiss confocal LSM 880 x63 lens. L: Left; R: Right.

- were developed here for application in a model microbial eukaryote. This provides a tool for both flavonoid therapeutic development and for use of $D$. discoideum in preclinical studies. To exploit DPBA further, future work will delimit its activity in vivo with a broader range of polyphenolic compounds of therapeutic interest - of which there are

\section{AUTHOR CONTRIBUTIONS}

BTF carried out experimental work and helped write the manuscript; EPT planned experiments and wrote the manuscript.

\section{FINANCIAL \& COMPETING INTERESTS DISCLOSURE}

The Rosetrees Trust part-funded this work. The authors have no other relevant affiliations or financial involvement with any organization or entity with a financial interest in or financial conflict with the subject matter or materials discussed in the manuscript apart from those disclosed.

No writing assistance was utilized in the production of this manuscript

\section{ACKNOWLEDGMENTS}

We thank Dudley Farman (LCMS); Ana Paleckyte (laboratory work); Dr Joanna Miest and Nine le Reun (translation); and Prof. Phil Stevenson and Prof. Jeremy Everett (useful discussions).

\section{OPEN ACCESS}

This work is licensed under the AttributionNonCommercial-NoDerivatives 4.0 Unported License. To view a copy of this license, visit http://creativecommons.org/licenses/ by-nc-nd/4.0/

\section{SUPPLEMENTARY DATA}

To view the supplementary data that accompany this paper please visit the journal website at: www.future-science. com/doi/suppl/10.2144/btn-2018-0084

\section{REFERENCES}

Papers of special note have been highlighted as: • of interest; $\cdot$ • of considerable interest. References 52 and 53 are in the associated Supplementary protocol

1. Dixon RA, Pasinetti GM. Flavonoids and isoflavonoids: from plant biology to agriculture and neuroscience. Plant Physiol. 154(2), 453-457 (2010).

2. Martínez-Pérez C, Ward C, Turnbull AK et al. Antitumour activity of the novel flavonoid Oncamex in preclinical breast cancer models. Br. J. Cancer 114(8), 905-916 (2016).

3. Spencer JPE, Crozier A. Flavonoids and related com pounds: bioavailability and function. CRC Press, FL USA (2012)

4. Abdel-Lateif K, Bogusz D, Hocher V. The role of flavonoids in the establishment of plant roots endosymbioses with arbuscular mycorrhiza fungi, rhizobia and Frankia bacteria. Plant Signal. Behav. 7(6), 636-641 (2012).

5. Brown DE. Flavonoids act as negative regulators of aux in transport in vivo in Arabidopsis. Plant Physiol. 126(2), 524-535 (2001)

6. Buer CS, Imin N, Djordjevic MA. Flavonoids: new roles for old molecules. J. Integr. Plant Biol. 52(1), 98-111 (2010).

7. Grootaert C, Gonzales GB, Vissenaekens $\mathrm{H}$ et al. Flow cytometric method for the detection of flavonoids in cell lines. J. Biomol. Screen. 21(8), 858-865 (2016). 
Method; cell type-dependent localization; no uptake of flavonoid glycosides was detected.

8. Peer WA, Murphy AS. Flavonoids as signal molecules. In: The Science of Flavonoids. Grotewold E (Ed.). Springer, Berlin, Germany, 239-268 (2006)

9. Thompson EP, Wilkins C, Demidchik V, Davies JM, Glove BJ. An Arabidopsis flavonoid transporter is required for anther dehiscence and pollen development. 61(2), 439-451 (2010).

10. Limer JL, Speirs V. Phyto-oestrogens and breast cancer chemoprevention. Breast Cancer Res. 6(3), 119-127 (2004).

11. Waheed A, Ludtmann MHR, Pakes $\mathrm{N}$ et al. Naringenin inhibits the growth of Dictyostelium and MDCK-derived cysts in a TRPP2 (polycystin-2)-dependent manner. $B r$. J. Pharmacol. 171(10), 2659-2670 (2014).

12. Brunetti C, Di Ferdinando M, Fini A, Pollastri S, Tattini M. Flavonoids as antioxidants and developmental regulators: relative significance in plants and humans. Int. $J$. Mol. Sci. 14(2), 3540-3555 (2013).

13. Hollman PCH. Absorption, bioavailability, and metabolism of flavonoids. Pharm. Biol. 42, 74-83 (2004).

14. Chen Z, Zheng S, Li L, Jiang $\mathrm{H}$. Metabolism of flavonoids in human: a comprehensive review. Curr. Drug Metab. 15(1), 48-61 (2014).

15. Nguyen TTT, Tran E, Ong CK et al. Kaempferol-induced growth inhibition and apoptosis in A549 lung cancer cells is mediated by activation of MEK-MAPK. J. Cell. Physiol. 197(1), 110-121 (2003).

16. Chen AY, Chen YC. A review of the dietary flavonoid, kaempferol on human health and cancer chemoprevention. Food Chem. 138(4), 2099-2107 (2014).

17. Russ M, Martinez R, Ali $H$, Steimle PA. Naringenin is a novel inhibitor of Dictyostelium cell proliferation and cell migration. Biochem. Biophys. Res. Commun. 345(1) 516-522 (2006)

18. Chirumbolo $S$. Quercetin in cancer prevention and therapy. Integr. Cancer Ther. 12(2), 97-102 (2013).

19. Stobiecki M, Kachlicki P. Isolation and identification of flavonoids. In: The Science of Flavonoids. Grotewold E (Ed.). Springer, Berlin, Germany, 47-69 (2006).

20. Wulandari L, Retnaningtyas Y, Nuri, Lukman H. Analysis of flavonoid in medicinal plant extract using infrared spectroscopy and chemometrics. J. Anal. Methods Chem. 2016 (2016)

21. Buer CS, Muday GK. The transparent testa4 mutation prevents flavonoid synthesis and alters auxin transport and the response of Arabidopsis roots to gravity and light. Plant Cell. 16, 1191-1205 (2004)

22. Peer WA. Flavonoid accumulation patterns of transparent Testa mutants of Arabidopsis. Plant Physiol. 126(2), 536-548 (2001).

23. Sheahan JJ, Rechnitz GA. Differential visualization of transparent testa mutants in Arabidopsis thaliana. Anal. Chem. 65(7), 961-963 (1993).

24. Vargo MA, Voss OH, Poustka F, Cardounel AJ, Grotewold E, Doseff Al. Apigenin-induced-apoptosis is mediated by the activation of PKC $\delta$ and caspases in leukemia cells. Biochem. Pharmacol. 72(6), 681-692 (2006).

25. Mukai R, Terao J, Shirai Y. Determination of subcellula localization of flavonol in cultured cells by laser scanning. Intech. 215-232 (2008)

26. Lee JH, Kim Y, Hoang MH, Jun H jin, Lee SJ. Rapid quantification of cellular flavonoid levels using quercetin and a fluorescent diphenylboric acid 2-amino ethyl ester probe. Food Sci. Biotechnol. 23(1), 75-79 (2014).

27. Saslowsky DE, Warek U, Winkel BSJ. Nuclear localization of flavonoid enzymes in Arabidopsis. J. Biol. Chem 1-12 (2001)

28. Neu R. Koordinierungsverbindungen aus diphenylborinsäure und substanzen mit stickstoff im ring als elektronendonator. Arch. de Pharm. 294(3), 173-178 (1961).

29. Brasseur TH, Angenot L. Un reactif de choix pour la revelation des flavonoids: Le melange diphenylborate d'aminoehtanol-peg 400. Lab de Pharm. 13, b139-141 (1986).

30. Matteini P, Agati G, Pinelli P, Goti A. Modes of complexation of rutin with the flavonoid reagent diphenylborinic acid 2-aminoethyl ester. Monatshefte fur Chemie. 142(9), 885-893 (2011)

-. Discussion of diphenylboric acid 2-aminoethyl ester mechanism of action.

31. Fey P, Gaudet P, Curk T et al. dictyBase - a Dictyostelium bioinformatics resource update. Nucleic Acids Res. 37(Suppl. 1), 515-519 (2009).

32. Kreppel L. dictyBase: a new Dictyostelium discoideum genome database. Nucleic Acids Res. 32(90001), 332D-333 (2004).

33. Otto GP, Sharma D, Williams RSB. Non-catalytic roles of presenilin throughout evolution. J. Alzheimer's Dis. 52(4), 1177-1187 (2016).
34. Garige $\mathrm{M}$, Walters $\mathrm{E}$. Curcumin inhibits development and cell adhesion in Dictyostelium discoideum: Implications for YakA signaling and GST enzyme function. Biochem. Biophys. Res. Commun. 467(2), 275-281 (2015).

35. Robery S, Tyson R, Dinh C et al. A novel human receptor involved in bitter tastant detection identified using Dictyostelium discoideum. J. Cell Sci. 126(23), 5465-5476 (2013).

36. Buer CS, Muday GK, Djordjevic MA. Flavonoids are differentially taken up and transported long distances in Arabidopsis. Plant Physiol. 145(2), 478-490 (2007).

37. Debeaujon I. The transparent testa1 2 gene of Arabidopsis encodes a multidrug secondary transporter-like protein required for flavonoid sequestration in vacuoles of the seed coat endothelium. Plant Cell Online. 13(4), 853-872 (2001).

38. Marinova K, Pourcel L, Weder B et al. The Arabidopsis MATE transporter TT12 acts as a vacuolar flavonoid/H -antiporter active in proanthocyanidin-accumulating cells of the seed coat. Plant Cell. 19(6), 2023-2038 (2007).

39. Mukai R, Shirai Y, Saito N, Yoshida KI, Ashida H. Subcellular localization of flavonol aglycone in hepatocytes visualized by confocal laser scanning fluorescence
microscope. Cytotechnology 59(3), 177-182 (2009).

40. Zhao J, Huhman D, Shadle $G$ et al. MATE2 mediates vacuolar sequestration of flavonoid glycosides and glycoside malonates in Medicago truncatula. Plant Cell. 23(4), 1536-1555 (2011).

41. Hostetler G, Riedl K, Cardenas H et al. Flavone deglycosylation increases their anti-inflammatory activity and absorption. Mol. Nutr. Food Res. 56(4), 558-569 (2012).

42. Hadi SM, Bhat SH, Azmi AS, Hanif S, Shamim U Ullah MF. Oxidative breakage of cellular DNA by plant polyphenols: a putative mechanism for anticancer properties. Semin. Cancer Biol. 17(5), 370-376 (2007)

43. Cai Q, Rahn RO, Zhang R. Dietary flavonoids, quercetin, luteolin and genistein, reduce oxidative DNA damage and lipid peroxidation and quench free radicals. Cancer Lett. 119(1), 99-107 (1997).
44. Van Es S, Wessels D, Soll DR, Borleis J, Devreotes PN. Tortoise, a novel mitochondrial protein, is required for directional responses of Dictyostelium in chemotactic gradients. J. Cell Biol. 153(3), 621-632 (2001).

45. Gilson PR, Yu X, Hereld D et al. Two Dictyostelium orthologs of the prokaryotic cell division protein FtsZ localize to mitochondria and are required for the main tenance of normal mitochondrial morphology. Euk. Cell. 2(6), 1315-1326 (2003).

46. Chen AY, Chen YC. A review of the dietary flavonoid kaempferol on human health and cancer chemoprevention. Food Chem. 138(4), 2099-2107 (2014).

47. Jaramillo-Carmona S, Lopez S, Abia R et al. Combination of quercetin and kaempferol enhances in vitro cytotoxicity on human colon cancer (HCT-116) cells. Rec. Nat. Prod. 8(3), 262-271 (2014).

48. Sak K. Site-specific anticancer effects of dietary flavo noid quercetin. Nutr. Cancer 66(2), 177-193 (2014).

49. Luo Y, Vassilev PM, Li X, Kawanabe Y, Zhou J. Native polycystin 2 functions as a plasma membrane $\mathrm{Ca} 2+-$ permeable cation channel in renal epithelia. Mol. Cell. Biol. 23(7), 2600-7 (2003).

50. Lima WC, Vinet A, Pieters J, Cosson P. Role of PKD2 in rheotaxis in Dictyostelium. PLoS One 9(2), (2014).

51. Xiao J. Dietary flavonoid aglycones and their glycosides: which show better biological significance? Crit. Rev. Food Sci. Nutr. 57(9), 1874-1905 (2017).

52. Eichinger L, Rivero F. Dictyostelium discoideum protocols. Methods in Molecular Biology. Humana Press, 346 (2006).

53. Hutzler $P$ Fischbach $R$, Heller $W$ et al. Tissue localization of phenolic compounds in plants by confocal laser scanning microscopy. J. Exp. Bot. 49, 953-965 (1998).
BioTechniques

TIME TO

RENEW YOUR SUBSCRIPTION

Subscriptions to BioTechniques need to be renewed every year. Don't miss out on all of the comprehensive reviews, novel research articles, and insightful features found each month in the pages of BioTechniques.

Renew Today and Choose Your Preferred Formats
Publishing in 2019

Tech News Features Animal Models and Virtual Reality Cell culture Neuroscience Sequencing Stem cells Special Reports How to transition from early career to established Reproducibility

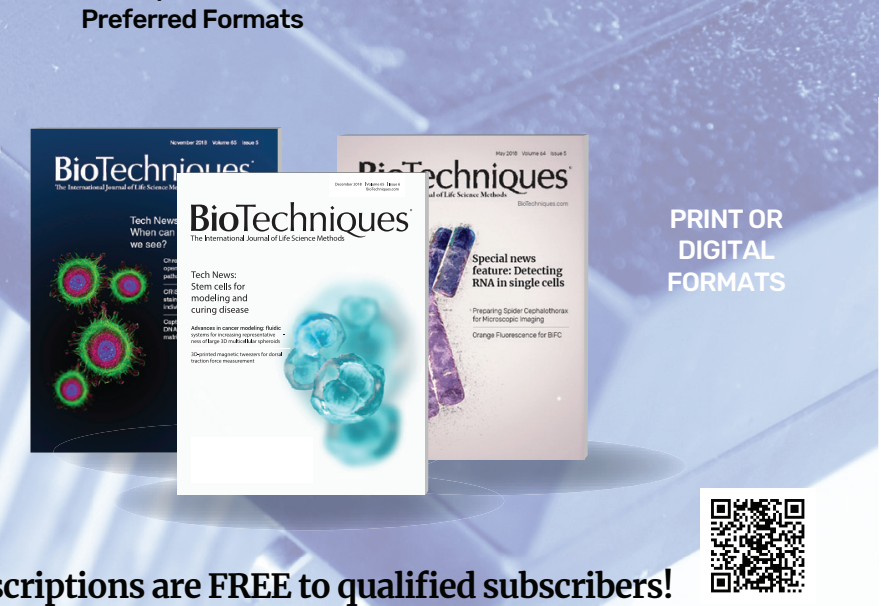

Subscriptions are FREE to qualified subscribers! 